\title{
Default and determinacy under quantitative easing
}

\author{
Nikolaos Romanidis ${ }^{1}$. Dimitrios P. Tsomocos ${ }^{2}$
}

Received: 20 October 2019 / Accepted: 12 April 2021 / Published online: 1 May 2021

(C) The Author(s) 2021

\begin{abstract}
We show that the path of inflation under quantitative easing policies that target interest rates, is determinate in the presence of default. We achieve this through different payoff profiles that a collateralised defaultable bond achieves in different states of nature with distinct default outcomes. In the model, heterogeneous households trade this bond and other shorter maturity risk-free bonds to maximize their intertemporal utility of consumption and labour. The differentiated payoffs of the collateralised bond, in an equilibrium with active default, span the full state space giving determinacy of prices and inflation as an outcome. This, implies that quantitative easing as implemented by the ECB in the recent years, can control the stochastic path of inflation.
\end{abstract}

Keywords Default · Collateral · Determinacy · Money · Quantitative easing

JEL Classification: D53 · E44 · D58

\section{Introduction}

The interconnection between the real and monetary parts of the economy creates the question of how price levels and inflation are being determined in equilibrium. In classical general equilibrium models, the price level is indeterminate as prices can only be pinned down in relative terms due to the Walras Law. In models, where money is introduced, price levels not only remain indeterminate but the introduction of money can also lead to indeterminacy of real allocations among agents, when markets

\footnotetext{
We are grateful to John Geanakoplos, Christina Laskaridis, Theofanis Papamichalis, Udara Peiris, Heracles Polemarchakis, two anonymous referees and seminar participants at the Summer Workshop in Economic Theory (SWET19) in memory of Martine Quinzii for their valuable comments. However, all remaining errors are ours.
}

$凶$ Dimitrios P. Tsomocos dimitrios.tsomocos@sbs.ox.ac.uk

1 Saïd Business School, Christ Church, University of Oxford, Oxford, UK

2 Saïd Business School, St Edmund Hall, University of Oxford, Oxford, UK 
are incomplete. Lin et al. (2016) show that the introduction of default remove the indeterminacy of price levels and inlation through the implementation of conventional monetary policy.

Conventional monetary policy puts limits on the central banks balance sheet and allows short dated government bonds only. Unconventional monetary policy, also known as, quantitative easing $(\mathrm{QE})$ removes this restriction on the assets the central bank can hold on its balance sheet and allows for assets of different credit risk and duration profiles. The Bank of England, the European Central Bank (ECB) and the Federal Reserve implemented QE both by targeting the aggregate level of asset purchases but also specifying restrictions on the composition of their portfolios whereas the Bank of Japan targeted only the the aggregate level of balances. McMahon et al. (2018) show that in a cash-in-advance monetary economy with flexible prices, unconventional monetary policy cannot determine the path of inflation.

The main goal of this paper is to establish, using a variant of the Lin et al. (2016) model, that the introduction of default in the setting of McMahon et al. (2018), resolves the indeterminacy of the price level and thus, the inflation path under QE. We hasten to add that this result obtains whenever there is default in all future states of nature and the central bank sets the collateral requirements exogenously. Thus, this implies that the QE that was implemented by the ECB in the recent years can be efficient in achieving the economic outcomes it seeks, part of which consists of determining the inflation path. Magill and Quinzii (1992) show, by using a variant of the Lucas Jr and Stokey (1987) model, that the central bank can determine the inflation path, if it purchases the whole endowment of agents in exchange of a fixed supply of money, which the agents then use to purchase back goods. In this setup, by construction, the money supply is determined, the quantity theory of money holds and the central bank can choose the price level through this fixed money supply. McMahon et al. (2018) show that, under quantitative easing, the inflation path is indeterminate when the supply of money is not fixed. They point out that indeterminacy can be lifted under different forms of quantitative easing. Dubey and Geanakoplos (2006) show that with the presence of outside money, monetary policy can achieve determinacy. We focus on showing that without the presence of outside money but with positive interest rates, which prevent agents from carrying over money from one period to the next, the introduction of default generates determinacy of the inflation path under unconventional monetary policy.

This paper replicates quantitative easing through a set of collateralised long term loans. When default is present in every state in the future for some of these collateralized long term loans, the payoff profile of these loans changes. This creates a set of payoffs that can span the full state space and combined with the distinct collateral profiles, these loans consist of a set of loans with different risk profiles which can replicate the different durations of bonds being purchased by the ECB. At the same time, the wealth forgone from defaulting on these long term loans is used to repay positive interest rate payments back to the central bank and thus, supports the presence of positive interest rates, and removing the need for outside money endowments since there is a cost of carrying money to the next period. Thus the quantity theory of money obtains and the central bank determines the price level and inflation path by targeting the interest rates of both the short term and long term loans. In addition, the collateral 
requirements on the long term loans ensures that there is default in every state in the future. Under interest rate targeting, the central bank targets positive interest rates, households use some of the money obtained by long term loans to repay short term loans at the end of the first period. Therefore, less money is endogenously transferred than the long term loan obtained to the second period, supporting default. Put differently, there do not exist enough liquid resources to pay off long term loans at the second period.

Goodhart et al. (2009) modelled default in a similar manner and studied the exacerbating effects of default in the business cycle during a housing crisis. Moreover, Lin et al. (2015) modelled default in a similar vein and assessed its impact on debt deflation. Related literature includes Huang et al. (2019), Bucher et al. (2020) and Gong and Phelan (2019).

The rest of the paper proceeds as follows: In Sect. 1.1, we present a summary of the various forms of QE that was implemented by the major central banks around the world. Section 2, presents the model, the agents' optimization problem and provides the market clearing conditions. Section 3 defines the equilibrium and provides the main propositions that are used to prove determinacy of price levels and inflation path under positive interest rate targets. Section 4 proves the main result of the paper, and shows determinacy. Finally, Sect. 5, concludes.

\section{The model}

We extend the model by McMahon et al. (2018) by including heterogeneous agents and default. Our goal is to show that default removes price and inflation indeterminacy under quantitative easing and gives rise to a unique inflation and price path. The idea is motivated by Lin et al. (2016). We consider a three-period model where the third period serves for accounting purposes and debts are settled in this date. There is uncertainty in the second period and each one of $S$ states can obtain. Nature selects one of the states $s_{1} \in\{1, \ldots, S\}$ which occurs in period 1 . State $s_{0}$ occurs in period 0 . There is one perishable good in the economy. There is also one durable real asset in the economy that pays out $X_{s_{1}}$ units or perishable good in state $s_{1}$ in period 1 . The asset payoffs can be viewed as a vector, $\mathbb{X}_{+}^{S}$, which is a $S \times 1$ vector.

Let the price for the perishable good be denoted by $p\left(s_{0}\right)$ in period 0 and by $p\left(s_{1} \mid s_{0}\right)=p\left(s_{1}\right)$ in period 1 . Let also the price of the real asset be denoted by $q\left(s_{0}\right)$ in period 0 . There is a set of households, $\mathbb{H}=\{1, \ldots, H\}$, where each agent is endowed with an initial endowment of the real asset at each period. Denote by $e^{h}\left(s_{0}\right)$ the endowment of real asset at period 0 by household $h$.

Production in the economy is modelled as in McMahon et al. (2018). At period $t$, a household, $h$, provides $l^{h}\left(s_{t}\right)$ units of labour to produce perishable goods,

$$
y^{h}\left(s_{t}\right)=l^{h}\left(s_{t}\right) .
$$


Utility of consumption and leisure is defined by

$$
U^{h}=u^{h}\left(c^{h}\left(s_{0}\right), 1-l^{h}\left(s_{0}\right)\right)+\beta \sum_{s_{1}} u^{h}\left(c^{h}\left(s_{1}\right), 1-l^{h}\left(s_{1}\right)\right)
$$

where $c^{h}\left(s_{t}\right)$ denotes consumption in period $\mathrm{t}$ and $u^{h}$ is continuously differentiable, strictly increasing, and strictly concave.

In the model, households trade in both the perishable good and the real asset. We denote by $\theta_{1}^{h}\left(s_{t}\right)$ the quantity of perishable goods purchased by household $h$ in period $\mathrm{t}$ and by $\theta_{2}^{h}\left(s_{t}\right)$, the quantity of perishable goods sold by the household in period $\mathrm{t}$. We denote by $\phi_{1}^{h}\left(s_{0}\right)$ the quantity of real assets purchased by household $h$ in period 0 , and by $\phi_{2}^{h}\left(s_{0}\right)$, the quantity of real assets sold by household $h$, in period 0 .

In the model, demand for money is introduced through a cash-in-advance constraint. All trades of goods and real assets are made in fiat money. Money can also be carried over to the next period. Households need to have cash at hand to make purchases at the beginning of each period. Households do not have initial nominal wealth (monetary endowments) but they obtain cash through short term and long term borrowing from the central bank. Short term borrowing in our model replaces the monetary endowments in the McMahon et al. (2018) model. Long term loans are collateralized and subject to default. ${ }^{1}$

In particular, short term loans are issued by the central bank at the beginning of each period $\mathrm{t}$, and promise a repayment of $\mu^{h}\left(s_{t}\right)$ at the end of period t. Long term loans are issued only in period 0 by the central bank, and promise a repayment of $\mu^{h}(d)$ at the beginning of period 1 and before any commodity trade. These long term loans are collateralized, and are indexed by $d \in \mathbb{D}=\{1, \ldots, D\}$, where each of these loans correspond to a unique collateral requirement $\delta_{d}$, which represents the nominal value of real assets required as collateral, per unit of loan $d$. The interest rate, on each of these loans, is denoted by $r(d)$ and on the short term loans by $r\left(s_{t}\right)$ in period $t$. This implies, that for a household $h$, to obtain a long term loan of size $\mu^{h}(d)$, the household needs to pledge $\delta_{d} / q\left(s_{0}\right)$ units of the real asset as collateral. Therefore, each household needs to satisfy a collateral constraint based on the amount of real asset it pledges i.e.,

$$
\sum_{d} \mu^{h}(d) \frac{\delta_{d}}{q\left(s_{0}\right)} \leq e^{h}\left(s_{0}\right)+\phi_{1}^{h}\left(s_{0}\right)-\phi_{2}^{h}\left(s_{0}\right) .
$$

At the beginning of period 1, each household decides on whether or not to default on the loan. The household defaults if the collateral value is less than the size of the loan and does not default otherwise. Thus, household, $h$, repays in state s, period 1 ,

$$
\mu^{h}(d) \times \min \left[1, \delta_{d} X_{s_{1}} \frac{p\left(s_{1}\right)}{q\left(s_{0}\right)}\right] .
$$

\footnotetext{
1 Without loss of generality, the short term loans are not defaultable. Had we allowed default, milder conditions would be necessary to establish determinacy, as it will be explained later.
} 
Define $R^{d}\left(s_{1}\right)=\min \left[1, \delta_{d} X_{s_{1}} \frac{p\left(s_{1}\right)}{q\left(s_{0}\right)}\right]$. The collateral requirements, $\delta_{d}$, are exogenous and set by the central bank.

The timeline of the model is as follows:

1. In the beginning of period 0 , households supply labour and produce, borrow short term and long term and trade in real assets and perishable goods.

2. At the end of period 0 , households repay their short term loan with their income and consume.

3. In the beginning of period 1 , households supply labour and produce, short term borrowing, decide whether to default or not on their long term loan obligations and trade in goods, and they may also roll over their collateralized long term loans with short term loans.

4. At the end of period 1, households repay their short term loans and consume.

5. In period 2, all outstanding liabilities have been repaid and money has exited the economy.

\subsection{Households}

Define,

$$
B(h)=\left\{l^{h}\left(s_{t}\right), \theta_{1}^{h}\left(s_{t}\right), \theta_{2}^{h}\left(s_{t}\right), \phi_{1}^{h}\left(s_{0}\right), \phi_{2}^{h}\left(s_{0}\right), \mu^{h}\left(s_{t}\right), \mu^{h}(d), c^{h}\left(s_{t}\right), m^{h}\left(s_{t}\right)\right\}
$$

where $m^{h}\left(s_{t}\right)$ is money left unused at the end of period t and transferred to next period. Household $h \in \mathbb{H}$, maximises its utility,

$$
\max _{B(h)} U^{h}=u^{h}\left(c^{h}\left(s_{0}\right), 1-l^{h}\left(s_{0}\right)\right)+\beta \sum_{s_{1}} u^{h}\left(c^{h}\left(s_{1}\right), 1-l^{h}\left(s_{1}\right)\right)
$$

subject to the following constraints,

$$
\hat{m}^{h}\left(s_{0}\right)=\frac{\mu^{h}\left(s_{0}\right)}{1+r\left(s_{0}\right)}+\sum_{d} \frac{\mu^{h}(d)}{1+r(d)}
$$

where $\hat{m}^{h}\left(s_{0}\right)$ is the cash used to purchase real assets and goods at the beginning of period 0 . This constraint implies that this cash should be equal to the cash available, which equal to the loans obtained.

$$
\hat{m}^{h}\left(s_{0}\right) \geq p\left(s_{0}\right) \theta_{1}^{h}\left(s_{0}\right)+q\left(s_{0}\right) \phi_{1}^{h}\left(s_{0}\right) .
$$

Equation (8) is the cash-in-advance constraint i.e., available cash is greater or equal than the total purchases in real assets and goods by household $h$.

$$
m^{h}\left(s_{0}\right)=\hat{m}^{h}\left(s_{0}\right)-p\left(s_{0}\right) \theta^{h}\left(s_{0}\right)-q\left(s_{0}\right) \phi^{h}\left(s_{0}\right)-\mu^{h}\left(s_{0}\right) \geq 0
$$


where $\theta^{h}\left(s_{0}\right)=\theta_{1}^{h}\left(s_{0}\right)-\theta_{2}^{h}\left(s_{0}\right)$ and $\phi^{h}\left(s_{0}\right)=\phi_{1}^{h}\left(s_{0}\right)-\phi_{2}^{h}\left(s_{0}\right)$. It is the money left at the end of period 0 , i.e., total cash minus net purchases of goods, minus net purchases of real assets, less short term loan repayment. This must be greater or equal than 0 .

$$
\sum_{d} \mu^{h}(d) \frac{\delta_{d}}{q\left(s_{0}\right)} \leq e^{h}\left(s_{0}\right)+\phi_{1}^{h}\left(s_{0}\right)-\phi_{2}^{h}\left(s_{0}\right) .
$$

Equation (10) is the collateral constraint that each household faces i.e., real assets pledged as collateral must be less that real assets endowed plus net purchases of real assets.

$$
c^{h}\left(s_{0}\right)=y^{h}\left(s_{0}\right)+\theta_{1}^{h}\left(s_{0}\right)-\theta_{2}^{h}\left(s_{0}\right) .
$$

Equation (11) is the consumption of household $h$ which should be equal to its output in period 0 plus its net purchases of perishable goods.

$$
p\left(s_{1}\right) \theta_{1}^{h}\left(s_{1}\right)+\sum_{d} \mu^{h}(d) \mathbb{I}^{d}\left(s_{1}\right) \leq m^{h}\left(s_{0}\right)+\frac{\mu^{h}\left(s_{1}\right)}{1+r\left(s_{1}\right)}
$$

where $\mathbb{I}^{d}\left(s_{1}\right)$ is the indicator function and is equal to 1 if household $h$ decides to repay and is equal 0 if the household decides to default. Equation(12) constraint shows that in period 1 and state $s_{1}$, money carried forward plus money borrowed short term are greater or equal than purchases of goods in state $s_{1}$ plus repayment on long term loan.

$$
m^{h}\left(s_{1}\right)=m^{h}\left(s_{0}\right)+\frac{\mu^{h}\left(s_{1}\right)}{1+r\left(s_{1}\right)}-p\left(s_{1}\right) \theta^{h}\left(s_{1}\right)-\sum_{d} \mu^{h}(d) \mathbb{I}^{d}\left(s_{1}\right)-\mu^{h}\left(s_{1}\right) \geq 0
$$

where $\theta^{h}\left(s_{1}\right)=\theta_{1}^{h}\left(s_{1}\right)-\theta_{2}^{h}\left(s_{1}\right)$. Money left at the end of period 1, i.e., money carried over plus money borrowed short term, less net purchases of goods, and long term debt repayment, and short term loan repayment. It should be greater or equal than 0 .

$$
e^{h}\left(s_{1}\right)=e^{h}\left(s_{0}\right)+\phi^{h}\left(s_{0}\right)-\sum_{d}\left(1-\mathbb{I}^{d}\left(s_{1}\right)\right) \mu^{h}(d) \frac{\delta_{d}}{q\left(s_{0}\right)} .
$$

Equation (14) is the real assets held by household $h$ in period 1, state $s_{1}$. This is equal to real assets endowed in the beginning of period 0 , plus net purchases of real assets by household $h$, less real assets seized by the central bank upon default.

$$
c^{h}\left(s_{1}\right)=y\left(s_{1}\right)+\theta^{h}\left(s_{1}\right)+e^{h}\left(s_{1}\right) X_{s_{1}} .
$$

Equation (15) is consumption of household $h$ in period 1 , state $s_{1}$. It is equal to output produced in period 1 , state $s_{1}$ by household $h$, plus net purchases of perishable goods by household $h$, plus payoff of real assets held by household $h$ in period 1 , state $s_{1}$.

Finally, Eq. (16) is the production by the household in both periods,

$$
y^{h}\left(s_{t}\right)=l^{h}\left(s_{t}\right) .
$$




\subsection{Central bank}

The central bank extends short-term and long term loans. It sets the interest rates and chooses the collateral requirements.

\subsection{Market clearing and equilibrium}

\subsubsection{Assets market}

For assets markets to clear, total purchases should be equal to total sales and thus,

$$
\sum_{h} \phi_{1}^{h}\left(s_{0}\right)=\sum_{h} \phi_{2}^{h}\left(s_{0}\right)
$$

\subsubsection{Goods market}

For goods markets to clear, total purchases should be equal to total sales, and hence,

$$
\sum_{h} \theta_{1}^{h}\left(s_{0}\right)=\sum_{h} \theta_{2}^{h}\left(s_{0}\right)
$$

and

$$
\sum_{h} \theta_{1}^{h}\left(s_{1}\right)=\sum_{h} \theta_{2}^{h}\left(s_{1}\right)+\sum_{h} \sum_{d}\left(1-\mathbb{I}^{d}\left(s_{1}\right)\right) \mu^{h}(d) \delta_{d} \frac{X_{s_{1}}}{q\left(s_{0}\right)}, \forall s_{1} \in S .
$$

\subsubsection{Short term money market}

Demand for short term loans must be equal to money supply,

$$
1+r\left(s_{t}\right)=\frac{\sum_{h} \mu^{h}\left(s_{t}\right)}{M\left(s_{t}\right)} .
$$

\subsubsection{Long term money market}

Demand for long term loans must be equal to money supply,

$$
1+r(d)=\frac{\sum_{h} \mu^{h}(d)}{M(d)} \quad \forall d \in \mathbb{D} \text {. }
$$

Definition $\left\{\left(r\left(s_{t}\right), r(d), p\left(s_{t}\right), q\left(s_{0}\right)\right),\left(M\left(s_{t}\right), M(d)_{d \in \mathbb{D}}\right), B(h)_{h \in \mathbb{H}}\right\}$ is a monetary collateral equilibrium (MCE) for the economy $\mathbb{E}=\left\{\left(U^{h}, e^{h}\left(s_{0}\right)\right)_{h \in \mathbb{H}}, \mathbb{X}_{+}^{S}\right.$, $\left.\left(\delta_{d}\right)_{d \in \mathbb{D}}\right\}$ if and only if all markets clear and expectations are rational, i.e., future prices and interest rates are correctly anticipated, and agents optimize given their budget sets. 


\section{Equilibrium analysis}

In this section, we will derive some preliminary results in order to prove the main goal of this paper which is determinacy of prices. First of all, we need to define QE in our setting and prove that this definition is equivalent to the one suggested by McMahon et al. (2018). Once this is done, we can proceed into showing that the presence of default removes price indeterminacy.

Definition 1 A balance sheet policy is unrestricted and termed as Quantitative Easing $(\mathrm{QE})$, if the shares of collateralized long term loans issued are determined in equilibrium, and the realised payoffs of the collateralized long term loans span the whole state space.

This definition captures the essence of QE as it was implemented, for example, by ECB since both the monetary aggregates are determined by setting interest rates and the collateral requirements specify the restriction applied to the admissible assets by the central bank.

According to McMahon et al. (2018), QE is defined as a balance sheet policy where the shares of Arrow securities held by agents, are endogenously determined. We will later show that this definition is equivalent to definition 1.

The set of propositions needed to show determinacy in the next section follow:

Proposition 1 Short term and long term interest rates are nonnegative in any monetary equilibrium i.e., $r\left(s_{t}\right) \geq 0$ and $r(d) \geq 0$ for all $d \in \mathbb{D}$ and $s_{t} \in S \cup\left\{s_{0}\right\}$.

Proof $r\left(s_{t}\right)$ is clearly greater or equal than zero, since, if it was negative, then the households could indefinitely borrow from the central bank and thus, the no arbitrage condition would fail. Now, lets assume that

$$
r(d)<r\left(s_{0}\right)
$$

for some $d \in \mathbb{D}$. Assume also that for this $d$, there is no default. If there was, then the interest rate would be certainly higher. Since demand is bounded, due to the need of posting collateral, $r(d)$ must be higher than $r\left(s_{0}\right)$. Else, the household would be willing to post more collateral to acquire further long-term loans. This yields a contradiction, and therefore $r\left(s_{t}\right) \geq 0$ and $r(d) \geq 0$ for all $d \in \mathbb{D}$ and $s_{t} \in S \cup\left\{s_{0}\right\}$, which concludes the proof.

Proposition 2 There is no cash left at the end of period 1 i.e., $m^{h}\left(s_{1}\right)=0$.

Proof We will prove this by contradiction. Assume that household $h$ has some unspent cash at the end of period 1 i.e., $m^{h}\left(s_{1}\right)>0$. Then by Eq. (13), the household could have borrowed a bit more at the beginning of period 1 in the short term money market, purchase more goods and hence, increase its consumption, and still have some money left. Since the agent maximizes its utility, this yields a contradiction, and thus

$$
m^{h}\left(s_{1}\right)=0 .
$$


Proposition 3 The term structure of interest rates is given by

$r\left(s_{0}\right) M\left(s_{0}\right)+r\left(s_{1}\right) M\left(s_{1}\right)+\sum_{d}\left[R^{d}\left(s_{1}\right) M(d)(1+r(d))-M(d)\right]=0, \quad \forall s_{1} \in S$.

Proof Summing Eqs. (7) and (9) over all households, and using the market clearing conditions (17), (18), (20) and (21) we get that

$$
\sum_{d} M(d)=r\left(s_{0}\right) M\left(s_{0}\right)+m\left(s_{0}\right)
$$

where $m\left(s_{0}\right)=\sum_{h} m^{h}\left(s_{0}\right)$.

In a similar fashion, summing Eq. (13) over all households, using market clearing conditions (18), (19) and (20) and also the result of proposition 3, we obtain

$$
r\left(s_{1}\right) M\left(s_{1}\right)+\sum_{d} R^{d}\left(s_{1}\right) M(d)(1+r(d))=m\left(s_{0}\right) .
$$

Finally, subtracting Eqs. (23) from (24) and re-arranging gives the desired result.

The following proposition investigates whether a household transfers money within each period.

Proposition 4 Assume that $r\left(s_{t}\right)>0, \forall s_{t} \in S \cup\left\{s_{0}\right\}$. Then, constraint (8) binds if the household borrows short term in period 0 i.e., $\mu^{h}\left(s_{0}\right)>0$ and constraint (12) always binds. However, constraint (8) might be slack if the household does not borrow short term in period 0 .

Proof Assume that $\mu^{h}\left(s_{0}\right)>0$ and that constraint (8) is slack. Then the household can reduce its short term borrowing by $\varepsilon\left(1+r\left(s_{0}\right)\right)$, without violating (8) and can also reduce its sales of good by $\varepsilon r\left(s_{0}\right) / p\left(s_{0}\right)$, without violating constraint (9). This again increases its utility since it increases its consumption. Thus, our initial assumption cannot be valid since there is a utility improving strategy. In case that $\mu^{h}\left(s_{0}\right)=0$, then the above proof does not work and thus the result might fail.

The same argument follows mutatis mutandis for period 1 and constraint (12). In this case short term borrowing is the only borrowing available and thus, the household will always borrow. This concludes the proof.

Proposition 5 If the household is selling goods in period 1, then the household must have borrowed short term in that period. However, if a household is selling goods in period 0 , then the household has not borrowed short term necessarily.

Proof The household would never sell in the last period if it had not borrowed short term since cash at the end is worthless. However, in the first period, the household might sell in order to save money for the next period. Furthermore, the household could have obtained the cash required for transactions only through long term loans only. Therefore, sales at the end of period 0 do not necessarily imply short term borrowing. 
Proposition 6 Households either sell or buy goods and either sell or buy real assets i.e.,

$$
\theta_{1}^{h}\left(s_{t}\right) \theta_{2}^{h}\left(s_{t}\right)=0 \text { and } \phi_{1}^{h}\left(s_{t}\right) \phi_{2}^{h}\left(s_{t}\right)=0, \quad \forall s_{t} \in S \cup\left\{s_{0}\right\} .
$$

Proof Suppose, on the contrary, that $\theta_{1}^{h}\left(s_{t}\right) \theta_{2}^{h}\left(s_{t}\right)>0$ for some $s_{t} \in S \cup\left\{s_{0}\right\}$. Assume further that $\mu^{h}\left(s_{t}\right)>0$. Then, the household can reduce the amount of short term loan in that state by $\varepsilon$, spend $\varepsilon$ less in the purchase of the good and sell $\frac{\varepsilon\left(1+r\left(s_{t}\right)\right)}{p\left(s_{t}\right)}$ less of the good. Overall, this strategy increases the household's utility since it increases its consumption without violating any constraint. This yields a contradiction.

Now assume that $\mu^{h}\left(s_{t}\right)=0$. That implies that $s_{t}=s_{0}$, since if $s_{t} \in S$, then the amount the household would borrow in the short term money market would be strictly positive in order to make sense for the household to sell goods. That implies that $\mu^{h}(d)>0$ for some long term loan $d$. Hence, the household can decrease its long term borrowing by $\varepsilon$, decrease its purchase of goods by $\varepsilon$ and sell $\frac{\varepsilon(1+r(d))}{p\left(s_{t}\right)}$ less of the good. That again would increase the household's utility since it increases its consumption and does not violate any of the constraints.

In a similar vein, we show that households either sell or buy real assets. That concludes the proof.

Proposition 7 If $\delta_{d} X_{s_{1}} \frac{p\left(s_{1}\right)}{q\left(s_{0}\right)}>1 \forall d \in \mathbb{D}$ and $\forall s_{1} \in S$, then

$$
r\left(s_{t}\right)=r(d)=0 \quad \forall s_{t} \in S \cup\left\{s_{0}\right\}, d \in \mathbb{D} .
$$

Proof By the assumption and Eq. (4), we conclude that there is no default on any contract $d$ and state $s$. Thus, Eq. (22) becomes

$$
r\left(s_{0}\right) M\left(s_{0}\right)+r\left(s_{1}\right) M\left(s_{1}\right)+\sum_{d} M(d) r(d)=0 \quad \forall s_{1} \in S
$$

which means, due to the positivity of money supplies, that

$$
r\left(s_{t}\right)=r(d)=0 \quad \forall s_{t} \in S \cup\left\{s_{0}\right\}, d \in \mathbb{D} .
$$

The above proposition states that if no default occurs in equilibrium on any state, then all interest rates are zero. That would lead to indeterminacy of prices and shows the importance of default, in our model, in determining the prices.

Proposition 8 Let $|\mathbb{D}| \geq|S|$. The central bank can choose the collateral requirements (i.e., $\exists \delta_{d}, d \in \mathbb{D}$ ), in such a way that default occurs in every state and the payoffs of these collateralised long term loans span the entire state space. ${ }^{2}$

\footnotetext{
${ }^{2}$ Had we allowed default in the short term loans then we could have supported default in every state without necessarily imposing $|\mathbb{D}| \geq|S|$.
} 
Proof The central bank has to pick collateral requirements $\delta_{d} d \in \mathbb{D}$, such that $\delta_{d} X_{s_{1}} \frac{p\left(s_{1}\right)}{q\left(s_{0}\right)}<1$ for any $d$ and the payoffs of these contracts span the entire state space. First, $\delta_{d}, d \in \mathbb{D}$ needs to be positive so that the contract to be bounded. ${ }^{3} \mathrm{We}$ can choose the real asset's payoffs $X_{s_{1}}$ for $s_{1} \in S$ such that $X_{s_{1}} p\left(s_{1}\right)$ for $s_{1} \in S$ are distinct and $\frac{q\left(s_{0}\right)}{p\left(s_{1}\right) X_{s_{1}}}$ for $s_{1} \in S$ are in an increasing order. Since the total number of contracts is at least $S$, we can select $\delta_{1}$ to be smaller than all of the ordered numbers, $\delta_{2}$ to be larger than the smallest of the ordered numbers and smaller than the rest, $\delta_{3}$ to be larger than the two smallest ordered numbers and smaller than the rest and so forth.

Hence, we ensure that the span of these payoffs is the same as the span of the following vectors

$$
\{(1,1, \ldots, 1),(0,1, \ldots, 1), \ldots,(0,0, \ldots, 1)\}
$$

and therefore, span the whole space, and default is present in every state.

Corollary 1 Assume that households trade in Arrow securities instead of collateralized long term loans. Let, QE be a balance sheet policy where the shares of Arrow securities held by households are determined in equilibrium. This definition is equivalent to definition 1, where households trade in collateralized long term loans.

Proof First of all, note that in both definitions the shares of the specified contracts are determined in equilibrium. ${ }^{4}$ In order to show the above, it is enough to show that there is a set of contracts i.e. collateralized loans, that span the the whole state space. But, this follows directly from the definitions and proposition 10.

The above corollary confirms that definition 1 applies and ensures that the interest rates are positive (we will later show that default is a necessary and sufficient condition for the interest rates to be positive).

We will now show that households can obtain collateralized long term loans and at the same time transfer cash from one period to the next. This is required in order to show that default is a necessary and sufficient condition for the interest rates to be positive.

Proposition 9 Household $h$ may transfer cash from one period to the next i.e. $m^{h}\left(s_{0}\right)>0$ and also borrow in the collateralised long term money market i.e. $\mu^{h}(d)>0$ for some $d \in \mathbb{D}$, simultaneously.

Proof First of all, household $h$ will not carry cash into the next period if the household does not default on its long term loan obligations. To illustrate this, assume that $m^{h}\left(s_{0}\right)>0$. Since, $r(d)>>r\left(s_{0}\right), \forall d \in \mathbb{D}$, household $h$ would be better off to decrease the level of cash carrying forward by $\varepsilon$, borrow therefore $\frac{\varepsilon}{1+r\left(s_{0}\right)}$ more in

\footnotetext{
${ }^{3}$ Prices are bounded since positive collateral requirements ensure that the demand for these loans is bounded.

${ }^{4}$ Note that since there is not a representative agent, endogeneity does not follow directly. However, under an interest rate target, the total issuance of each of the collateralized long term loans is endogenously determined, and hence since each contract clears in a different market, the shares are also endogenous.
} 
the short term money market and borrow $\frac{\varepsilon}{1+r\left(s_{0}\right)}$ less in the long term money market. Then, in the beginning of period 1 , household $h$ will hold $\varepsilon$ less cash and will also repay $\frac{\varepsilon(1+r(d))}{1+r\left(s_{0}\right)}>>\varepsilon$, less on the long term loan and therefore, household $h$ will be better off.

However, in the case that the household does default on its long term loan obligations in period 1 , then it might carry cash forward from period 0 . To illustrate this consider the first order condition for $m^{h}\left(s_{0}\right)$, using Eqs. (7), (8), (9), (11) and (15),

$$
\sum_{s_{1}} \frac{\vartheta U^{h} / \vartheta c^{h}\left(s_{1}\right)}{p\left(s_{1}\right)}=\frac{1}{1+r\left(s_{0}\right)} \frac{\vartheta U^{h} / \vartheta c^{h}\left(s_{0}\right)}{p\left(s_{0}\right)} .
$$

for $m^{h}\left(s_{0}\right)>0$, if the household borrows short term in period 0 , and

$$
\sum_{s_{1}} \frac{\vartheta U^{h} / \vartheta c^{h}\left(s_{1}\right)}{p\left(s_{1}\right)}=\frac{\vartheta U^{h} / \vartheta c^{h}\left(s_{0}\right)}{p\left(s_{0}\right)} \text {. }
$$

$m^{h}\left(s_{0}\right)>0$, if the household does not borrow short term in period 0 .

The first order condition for long term loans, using (1)-(15), is,

$$
(1+r(d)) \sum_{s_{1}} \frac{\vartheta U^{h} / \vartheta c^{h}\left(s_{1}\right)}{p\left(s_{1}\right)} R^{d}\left(s_{1}\right)+\lambda^{h} \frac{\delta_{d}}{q\left(s_{0}\right)}=\frac{\vartheta U^{h} / \vartheta c^{h}\left(s_{0}\right)}{p\left(s_{0}\right)}, \quad \forall d \in \mathbb{D} .
$$

where, $\lambda^{h}$ is the lagrange multiplier linked to the binding collateral constraint for the real asset.

Combining (25), (26) and (27) gives that

$$
(1+r(d)) \sum_{s_{1}} \frac{\vartheta U^{h} / \vartheta c^{h}\left(s_{1}\right)}{p\left(s_{1}\right)} R^{d}\left(s_{1}\right)+\lambda^{h} \frac{\delta_{d}}{q\left(s_{0}\right)}=\left(1+r\left(s_{0}\right)\right) \sum_{s_{1}} \frac{\vartheta U^{h} / \vartheta c^{h}\left(s_{1}\right)}{p\left(s_{1}\right)}
$$

or

$$
(1+r(d)) \sum_{s_{1}} \frac{\vartheta U^{h} / \vartheta c^{h}\left(s_{1}\right)}{p\left(s_{1}\right)} R^{d}\left(s_{1}\right)+\lambda^{h} \frac{\delta_{d}}{q\left(s_{0}\right)}=\sum_{s_{1}} \frac{\vartheta U^{h} / \vartheta c^{h}\left(s_{1}\right)}{p\left(s_{1}\right)} .
$$

For the household $h$ to transfer cash to the next period and to borrow long term one of the above equations needs to be satisfied. Since $R^{d}\left(s_{1}\right)<1$, for defaulted loans, we have that the second from the above equations can always be satisfied, which concludes the proof.

Finally, in this section we proceed into showing that positive interest rates can be supported under the presence of default.

Proposition 10 There exist interest rates $r(d)>0$ and collateral requirements $\delta_{d}$, $\forall d \in \mathbb{D}$, such that all short term interest rates $r\left(s_{t}\right)$ are positive when $0<m\left(s_{0}\right)=$ $\sum_{h} m^{h}\left(s_{0}\right)<\sum_{d} M(d)$. 
Proof Since $0<m\left(s_{0}\right)=\sum_{h} m^{h}\left(s_{0}\right)<\sum_{d} M(d)$, we have by Eq. (23) that $r\left(s_{0}\right) M\left(s_{0}\right)>0$. Thus, $r\left(s_{0}\right)>0$. Moreover, by Eq. $(24)$, we have that

$$
r\left(s_{1}\right) M\left(s_{1}\right)+\sum_{d} R^{d}\left(s_{1}\right) M(d)(1+r(d))=m\left(s_{0}\right) .
$$

Therefore, by suitably choosing collateral requirements, $\delta_{d}, \forall d \in \mathbb{D}$, the central bank can decide which loans will be repaid in full i.e. $R^{d}\left(s_{1}\right)=1$ and which not such that the above equation holds for positive $r\left(s_{1}\right)$, which can happen in equilibrium, since $0<m\left(s_{0}\right)=\sum_{h} m^{h}\left(s_{0}\right)$.

\section{Determinacy}

Having proved the propositions in the previous section, we are ready to prove our main result which is the determinacy of prices and inflation under quantitative easing (as defined in definition 1) in the presence of default. Under interest rate targets, the central bank sets the interest rates and the collateral requirements. As we have already seen, in proposition 8, the central bank can set the collateral requirements such that there is active default in every state. Moreover, due to proposition 10, active default suffices to support positive interest rates in every state and period in equilibrium. Finally, due to proposition 4 , households do not transfer money within periods, i.e., constraint (8) binds.

The above suffices to show determinacy of prices and inflation. To proceed with the proof, we need to show that there is an equal number of equations and unknown variables to be determined as this suffices for uniqueness. Finally, the existence of the monetary equilibrium through proving the transversality theorem, can be found in Tsomocos (2003).

The central bank, as mentioned above, targets the collateral requirements, $\left(\delta_{d}\right)_{d \in \mathbb{D}}$, and the interest rates, $\left((r(d))_{d \in \mathbb{D}},\left(r\left(s_{t}\right)\right)_{s_{t} \in\left\{s_{0}\right\} \cup S}\right)$. The endogenous variables of the economy are $\left((M(d))_{d \in \mathbb{D}},\left(M\left(s_{t}\right)\right)_{s_{t} \in\left\{s_{0}\right\} \cup S},\left(p\left(s_{t}\right)\right)_{s_{t} \in\left\{s_{0}\right\} \cup S}\right.$, $q\left(s_{0}\right),\left(c^{h}\left(s_{t}\right)\right)_{s_{t} \in\left\{s_{0}\right\} \cup S}, \quad\left(\theta_{1}^{h}\left(s_{t}\right)\right)_{s_{t} \in\left\{s_{0}\right\} \cup S}, \quad\left(\theta_{2}^{h}\left(s_{t}\right)\right)_{s_{t} \in\left\{s_{0}\right\} \cup S}, \quad \phi_{1}^{h}\left(s_{0}\right), \phi_{2}^{h}\left(s_{0}\right)$, $\left.\left(\mu^{h}\left(s_{t}\right)\right)_{s_{t} \in\left\{s_{0}\right\} \cup S},\left(\mu^{h}(d)\right)_{d \in \mathbb{D}},\left(l^{h}\left(s_{t}\right)\right)_{s_{t} \in\left\{s_{0}\right\} \cup S}, \lambda^{h}\right)_{h \in \mathbb{H}}$.

These variables will be determined by the budget constraints (7)-(16) and the clearing conditions (17)-(21), along with the first order conditions for $m^{h}\left(s_{0}\right), \mu^{h}(d)$, $\phi_{1}^{h}\left(s_{0}\right), \phi_{2}^{h}\left(s_{0}\right)$ and the complementarity slackness condition for the collateral constraint.

We have that, the first order condition for $m^{h}\left(s_{0}\right)$ is

$$
\sum_{s_{1}} \frac{\vartheta U^{h} / \vartheta c^{h}\left(s_{1}\right)}{p\left(s_{1}\right)}=\frac{1}{1+r\left(s_{0}\right)} \frac{\vartheta U^{h} / \vartheta c^{h}\left(s_{0}\right)}{p\left(s_{0}\right)},
$$

if the household borrows short term in period 0 , and

$$
\sum_{s_{1}} \frac{\vartheta U^{h} / \vartheta c^{h}\left(s_{1}\right)}{p\left(s_{1}\right)}=\frac{\vartheta U^{h} / \vartheta c^{h}\left(s_{0}\right)}{p\left(s_{0}\right)},
$$


if the household does not borrow short term in period 0 .

The first order condition for long term loans is,

$$
(1+r(d)) \sum_{s_{1}} \frac{\vartheta U^{h} / \vartheta c^{h}\left(s_{1}\right)}{p\left(s_{1}\right)} R^{d}\left(s_{1}\right)+\lambda^{h} \frac{\delta_{d}}{q\left(s_{0}\right)}=\frac{\vartheta U^{h} / \vartheta c^{h}\left(s_{0}\right)}{p\left(s_{0}\right)}, \quad \forall d \in \mathbb{D} \text {. }
$$

The first order condition for purchases of the real asset is given by

$$
\sum_{s_{1}} \frac{\vartheta U^{h} / \vartheta c^{h}\left(s_{1}\right)}{p\left(s_{1}\right)} X_{s_{1}} p\left(s_{1}\right)+\lambda^{h}-\frac{q\left(s_{0}\right)}{p\left(s_{0}\right)} \vartheta U^{h} / \vartheta c\left(s_{0}\right)=0,
$$

and for sales is given by

$$
\left(1+r\left(s_{0}\right)\right) \sum_{s_{1}} \frac{\vartheta U^{h} / \vartheta c^{h}\left(s_{1}\right)}{p\left(s_{1}\right)} X_{s_{1}} p\left(s_{1}\right)+\lambda^{h}-\frac{q\left(s_{0}\right)}{p\left(s_{0}\right)} \vartheta U^{h} / \vartheta c\left(s_{0}\right)=0 .
$$

The complementary slackness condition for the collateral constraint is

$$
\lambda^{h}\left(\sum_{d} \mu^{h}(d) \frac{\delta_{d}}{q\left(s_{0}\right)}-e^{h}\left(s_{0}\right)-\phi_{1}^{h}\left(s_{0}\right)+\phi_{2}^{h}\left(s_{0}\right)\right)=0 .
$$

By proposition 3, we know that the endogenous variables

$$
\left((M(d))_{d \in \mathbb{D}},\left(M\left(s_{t}\right)\right)_{s_{t} \in\left\{s_{0}\right\} \cup S},\left(p\left(s_{t}\right)\right)_{s_{t} \in\left\{s_{0}\right\} \cup S}, q\left(s_{0}\right),\left(c^{h}\left(s_{t}\right)\right)_{s_{t} \in\left\{s_{0}\right\} \cup S}\right)
$$

will be determined by Eqs.(11), (15) and the clearing conditions. The variable

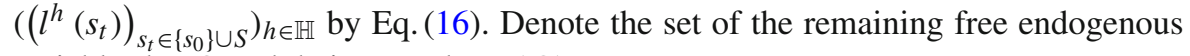
variables by $\Omega$ and their range by $I(\Omega)$.

\begin{tabular}{ll}
\hline Free variable & Equations \\
\hline$\phi_{1}^{h}\left(s_{t}\right), \phi_{2}^{h}\left(s_{t}\right) s_{t} \in S h \in \mathbb{H}$ & Equations (7), (8), (12), (13), (28), (29) \\
$\phi_{1}^{h}\left(s_{0}\right), \phi_{2}^{h}\left(s_{0}\right) h \in \mathbb{H}$ & Equations (32), (33) \\
$\mu^{h}\left(s_{t}\right) s_{t} \in\left\{s_{0}\right\} \cup S h \in \mathbb{H}$ & Equations (9), (13) \\
$\mu^{h}(d) d \in \mathbb{D} h \in \mathbb{H}$ & Equation (30) \\
$\lambda^{h} h \in \mathbb{H}$ & Equation (33) \\
$m^{h}\left(s_{0}\right)$ & Equations (28), (29) \\
$\hat{m}^{h}\left(s_{0}\right), m^{h}\left(s_{1}\right) s_{1} \in S$ & Proposition 4 or Eq. (9) \\
\hline
\end{tabular}

Define the set of utility functions for household $h \in \mathbb{H}$, as

$$
\mathbb{U}^{h}=\left\{u^{h}, u^{h}(c, 1-l)=\hat{u}^{h}(c, 1-l)+\alpha c \mid \alpha \in \mathbb{R}^{S^{*}}\right\}
$$


and

$$
\mathbb{U}=\times_{h \in \mathbb{H}} \mathbb{U}^{h} .
$$

Every free endogenous variable in $\Omega$ is derived by an equation from the remaining equations. In each of these equations move the RHS to the LHS so as LHS-RHS $=0$ in equilibrium. Define globally the following map

$$
\Pi: \mathbb{U} \times I(\Omega) \rightarrow \mathbb{R}^{k} \quad \Pi(u, \Omega)=R H S
$$

where $k$ is the dimension of $I(\Omega)$ and RHS refers to the RHS of the re-arranged equations. Thus, if $\Omega \in I(\Omega)$ represents an equilibrium, then $\Pi(u, \Omega)=0$. Thus, for an equilibrium to exist and be unique we must have that $\Pi_{u}^{-1}(0)$ must be a zerodimensional manifold. The uniqueness is implied by the equal number of unknowns and equations and the existence by the fact that $\Pi_{u}: I(\Omega) \rightarrow \mathbb{R}^{k}$ is transverse to 0 . The following theorem proves that this holds when the central bank targets strictly positive interest rates and sets the collateral requirements in such a way such that there is default in every state on some long term loan in period 1.

Theorem 1 The full set of equilibrium outcomes is determinate for a generic $u$ in $\mathbb{U}$ when the central bank targets strictly positive interest rates $\left((r(d))_{d \in \mathbb{D}}\right.$, $\left.\left(r\left(s_{t}\right)\right)_{s_{t} \in\left\{s_{0}\right\} \cup S}\right)$ and sets collateral requirements $\delta_{d}, d \in \mathbb{D}$ such that there is default in exactly one long term loan $d$ in every state s, assuming that for every agent $h$ and for all collateralised long term loans $d$, the real payoff of a riskless bond is $1 / q\left(s_{0}\right)$, the real payoff of the long term collateralised loan is $R^{d} / q\left(s_{0}\right), d \in \mathbb{D}$ and the real payoff of the real asset $\frac{X_{s_{1}} p\left(s_{1}\right)}{q\left(s_{0}\right)}$ are linearly independent. Moreover, $|\mathbb{D}| \geq|S|$.

Proof We start by considering the first order conditions for $m^{h}\left(s_{0}\right)$, the long term loans and the asset. By following proposition 9, Eqs. (29) and (30) can either be considered together or not. Based on the above assumption that the vectors of the real payoff of a riskless bond $1 / q\left(s_{0}\right)$, the real payoff of the long term collateralised loan $R^{d} / q\left(s_{0}\right), d \in \mathbb{D}$ and the real payoff of the real asset $\frac{X_{s_{1}} p\left(s_{1}\right)}{q\left(s_{0}\right)}$ are linearly independent, we can adjust $\frac{\vartheta U^{h} / \vartheta c^{h}\left(s_{1}\right)}{p\left(s_{1}\right)}$ in a direction which is orthogonal in all except one of the above vectors. Thus, we can unilaterally perturb any from the equations in this set.

To perturb Eq. (10), choose $\delta_{d}$ without changing $\mathbb{I}^{d}\left(s_{1}\right)$. To perturb Eqs. (7) and (8) increase $\mu^{h}\left(s_{0}\right)$ by $\varepsilon>0$, resulting in that $h$ spends $\frac{\varepsilon}{1+r\left(s_{0}\right)}$ more in her purchases. This disturbs Eq. (9) since some other agents receive $\varepsilon^{h}$ more. Assuming that one other agent receives them all, we must have that $\varepsilon^{h}=\frac{\varepsilon}{1+r\left(s_{0}\right)}$. We proceed by considering two different cases.

Suppose that this subsequent agent that receives all, increases her borrowing, and thus, can increase her purchases by $\frac{\varepsilon}{\left(1+r\left(s_{0}\right)\right)^{2}}$. Continuing with this logic, and the fact that each subsequent agent can borrow at the same interest rate $r\left(s_{0}\right)$, the total increase in borrowing is $\sum_{0}^{\alpha} \frac{\varepsilon}{\left(1+r\left(s_{0}\right)\right)^{n}}=\frac{\left(1+r\left(s_{0}\right)\right) \varepsilon}{r\left(s_{0}\right)}$, and hence, the total increase in spending goes up by $\frac{\varepsilon}{r\left(s_{0}\right)}$ which is finitely small.

Suppose that the subsequent agent $h$ does not increase her borrowing. Then, this means, that she would carry the amount $\varepsilon^{h}$ into the next period and will increase her 
purchases in the next period by this amount which will be transferred to another agent $h^{1}$ and hence, $\varepsilon^{h^{1}}=\frac{\varepsilon}{1+r\left(s_{1}\right)}$. From this point we return to case 1 , and thus the total borrowing and purchases will increase by a finitely small amount.

It follows that $p\left(s_{0}\right), p\left(s_{1}\right), c^{h}\left(s_{0}\right)$ and $c^{h}\left(s_{1}\right)$ also change by a finitely small amount for all $h \in \mathbb{H}$. Perturbing utility functions can restore the ratio $\frac{\vartheta U^{h} / \vartheta c^{h}\left(s_{1}\right)}{p\left(s_{1}\right)}$. The proofs for the remaining equations follow the same logic. To perturb Eq. (33), adjust $\mu^{h}(d)$ for some $d \in \mathbb{D}$. We re-adjust as above.

Therefore, the mapping $\Pi_{u}: I(\Omega) \rightarrow \mathbb{R}^{k}$ is transverse to 0 , proving the determinacy of monetary outcomes, i.e., the path of prices and inflation.

\section{Concluding remarks}

This paper presented a model that features trade in fiat money, one physical good, one real asset, riskeless short term loans and collateralized risky long term loans. It was shown that under Quantitative Easing policies under which the central bank purchases bonds with a plethora of credit risk and duration profiles, the price level and inflation path is determined when the central bank targets positive interest rates and decides the collateral requirements of the bonds in such way that default is present in every state of the world in the final period of the model. Default is an outcome when the value of the collateral is less that the repayment on the long term collateralized loan. The support of positive interest rates arises from the presence of default since the extra loss of monetary wealth by the ECB - similarly for the Bank of England and the Federal Reserve-is replaced by interest rate payments. This, in turn, makes agents not to transfer money from the first period to the second since there is a positive cost associated with obtaining loans. Thus, the bank makes losses in its long term lending but makes profits in its short term lending through the positive interest rates. Further research is warranted to endogenize collateral requirements as well as loosen the requirement that default ocurs in every state of nature.

Open Access This article is licensed under a Creative Commons Attribution 4.0 International License, which permits use, sharing, adaptation, distribution and reproduction in any medium or format, as long as you give appropriate credit to the original author(s) and the source, provide a link to the Creative Commons licence, and indicate if changes were made. The images or other third party material in this article are included in the article's Creative Commons licence, unless indicated otherwise in a credit line to the material. If material is not included in the article's Creative Commons licence and your intended use is not permitted by statutory regulation or exceeds the permitted use, you will need to obtain permission directly from the copyright holder. To view a copy of this licence, visit http://creativecommons.org/licenses/by/4.0/.

\section{References}

Bucher, M., Hauck, A., Neyer, U.: Interbank market friction-induced holdings of precautionary liquidity: implications for bank loan supply and monetary policy implementation. Econ. Theory 70(1), 165-222 (2020). https://doi.org/10.1007/s00199-019-01207-6

Dubey, P., Geanakoplos, J.: Determinacy with nominal assets and outside money. Econ. Theory 27(1), 79-106 (2006). https://doi.org/10.1007/s00199-004-0591-4 
Gong, F., Phelan, G.: Debt collateralization, capital structure, and maximal leverage. Econ. Theory 70, 579-605 (2020). https://doi.org/10.1007/s00199-019-01222-7

Goodhart, C.A.E., Tsomocos, D.P., Vardoulakis, A.P.: Modeling a housing and mortgage crisis. Documentos de Trabajo (Banco Central de Chile) (547):1 (2009)

Huang, K.X.D., Meng, Q., Xue, J.: Money growth targeting and indeterminacy in small open economies. Econ. Theory 68(3), 499-535 (2019). https://doi.org/10.1007/s00199-018-1132-X

Lin, L., Tsomocos, D.P., Vardoulakis, A.P.: Debt deflation effects of monetary policy. J. Financ. Stab. 21, 81-94 (2015)

Lin, L., Tsomocos, D.P., Vardoulakis, A.P.: On default and uniqueness of monetary equilibria. Econ. Theory 62(1-2), 245-264 (2016). https://doi.org/10.17016/FEDS.2015.034

Lucas Jr, R.E., Stokey, N.L.: Money and interest in a cash in advance economy. Econometrica 55(3), 491 (1987)

Magill, M., Quinzii, M.: Real effects of money in general equilibrium. J. Math. Econ. 21(4), 301-342 (1992)

McMahon, M., Peiris, M.U., Polemarchakis, H.: Perils of unconventional monetary policy. J. Econ. Dyn. Control 93, 92-114 (2018)

Tsomocos, D.P.: Equilibrium analysis, banking and financial instability. J. Math. Econ. 39(5-6), 619-655 (2003)

Publisher's Note Springer Nature remains neutral with regard to jurisdictional claims in published maps and institutional affiliations. 